\title{
Experimental assessment and modeling evaluation of the effects of the seagrass Posidonia oceanica on flow and particle trapping
}

\author{
Iris E. Hendriks ${ }^{1, *}$, Tomas Sintes ${ }^{2}$, Tjeerd J. Bouma ${ }^{3}$, Carlos M. Duarte ${ }^{1}$ \\ ${ }^{1}$ Instituto Mediterraneo de Estudios Avanzados, IMEDEA (CSIC-UIB), 07190 Palma de Mallorca, Spain \\ ${ }^{2}$ Departament de Física, Universitat de les Illes Balears, 07071 Palma de Mallorca, Spain \\ ${ }^{3}$ Netherlands Institute of Ecology (NIOO-KNAW), Centre for Estuarine and Marine Ecology (CEME), PO Box 140, \\ 4400 AC Yerseke, The Netherlands
}

\begin{abstract}
Retention of particles in seagrass canopies is usually attributed to only the indirect, attenuating effects canopies have on flow, turbulence and wave action, promoting sedimentation and reducing resuspension within seagrass meadows. Yet recent evidence suggests that seagrasses are also able to affect particle flux directly through loss of momentum and increased path length derived from collisions with leaves and binding of particles. We evaluated the role of Posidonia oceanica on flow and associated particle trapping through flume experiments. Our results confirm the existence of 2 dynamically different environments, viz. (1) the below-canopy habitat, with low shear stress and reduced turbulence, and (2) the canopy-water interface region, characterized by high shear stress and turbulence intensity, where vertical transport of momentum is enhanced. At relatively low free stream velocities (i.e. 0.05 and $0.10 \mathrm{~m} \mathrm{~s}^{-1}$ ) sediment concentration decreased much faster when a Posidonia meadow was present in the flume, indicating major particle trapping in the seagrass canopy. Fluxes to the sediment (as shown by large negative peaks in Reynolds stress inside the Posidonia meadow) indicated 2 to 6 times more sediment transport to the bottom when a meadow is present. However, calculations based on the experimental results point to loss rates an order of magnitude larger in a Posidonia meadow. We hypothesize that direct effects of particle collisions with leaves are responsible for this discrepancy, and we explore possible interactions with a simple model. Using only collisions as a loss factor, the model predicts that the probability a particle is lost from the flow upon a collision is 2 to $3 \%$. Previously observed leaf density and flow velocity effects on particle loss rates were explained by the model. Fitting the model to our experimentally obtained particle disappearance rates in vegetation indicated that around $27 \%$ of particle momentum is lost upon each collision with a leaf. We hypothesize that physical filtration by sediment collisions with plant structures plays a role in particle removal in aquatic systems.
\end{abstract}

KEY WORDS: Particle trapping $\cdot$ Physical filtering $\cdot$ Seagrass

Resale or republication not permitted without written consent of the publishe

\section{INTRODUCTION}

Seagrass canopies are known to reduce flow and turbulence (Fonseca et al. 1982, Gambi et al. 1990, Ackerman \& Okubo 1993, Koch 1996, Gacia et al. 1999, Koch \& Gust 1999, Nepf \& Vivoni 2000, Jumars et al. 2001, Peterson et al. 2004, Koch et al. 2006) and attenuate wave action (Fonseca \& Cahalan 1992, Koch \& Gust 1999, Granata et al. 2001, Bouma et al. 2005, Koch et al. 2006), thereby promoting sedimentation and reducing resuspension within seagrass meadows (Gacia et al. 1999, Terrados \& Duarte 2000, Gacia \& Duarte 2001). Examination of the composition of the material deposited within seagrass canopies has revealed the presence of a large (>50\%) contribution of sestonic particles (Gacia et al. 2002), pointing to a large pelagic particle flux toward seagrass meadows. These effects are clearly established and contribute to making seagrass meadows one of the most valuable habitats in the coastal zone (Hemminga \& Duarte 2000). 
Explaining the full mechanism by which seagrasses enhance particle retention is less clear. Usually, it is assumed that the role of seagrasses is solely indirect, driven by their effects on flow (Fonseca et al. 1983, Ackerman \& Okubo 1993, Lopez \& Garcia 1998, Granata et al. 2001). Yet recent evidence suggests that once particles are brought near the canopy (through the effects on flow listed above), seagrasses also affect particle flux directly, leading to potentially high particle removal rates (Agawin \& Duarte 2002). Possible mechanisms for such direct effects on particle trapping include (1) the loss of momentum and increased path length derived from collisions of the particles with leaves within the dense seagrass canopies, and (2) the direct binding of particles onto seagrass leaves by e.g. adhesion to exopolymeric substances excreted by epiphytes. Seagrass canopies increase the effective benthic surface as much as twenty fold, thereby providing a large surface for sediment deposition and increasing the probability of contact and subsequent trapping of sestonic particles on the seagrass leaves. Indeed, Agawin \& Duarte (2002) report particles adhering to seagrass surfaces, thereby confirming such binding capacity. In addition to this study on seagrasses, direct particle capture onto vegetation has been shown for salt marsh vegetation consisting of Juncus roemerianus (Leonard et al. 1995) and Spartina alterniflora (Stumpf 1983), for artificial structures mimicking plants (Hosokawa \& Horie 1992) and at small scales with low Reynolds numbers for cylindrical collectors in a flume (Palmer et al. 2004). Although all these results suggest that physical filtration by plant structures may play a role in particle removal by aquatic vegetation such as seagrasses, quantitative estimates of the relative importance of such direct trapping versus indirect trapping by flow reduction are limited (i.e. benthic chamber experiments in a Philippine reef-lagoon by Agawin \& Duarte (2002). Additional evidence for physical filtration points to a role for seagrasses as active filters, and strengthens our knowledge of the processes involved in particle capture by these important ecosystem engineers. Our aim is to clarify the 2 processes leading to entrapment of particles, viz. (1) initial retention above the canopy due to its effects on flow and (2) final capture by direct presence of leaves, a component normally overlooked in particle trapping estimates.

In this study we focused on the potential importance of direct trapping by collisions versus indirect trapping by flow reduction caused by the canopy. In order to resolve these aspects we first characterized the effects of the plants on flow by quantifying the role of Posidonia oceanica canopies on flow velocity, turbulence and shear stress at different flow velocities. These estimates were then used to evaluate sediment transport due to the altered hydrodynamics. We then compared this to measured sediment trapping, unraveling the effects of the vegetation from background retention, and finally we used a simple model to illustrate how particle trapping may be realistically explained by collisions, incorporating the observed flow regimes and particles loss rates as model inputs. Because field experiments in benthic chambers, such as those used by Agawin \& Duarte (2002), have severely disturbed flow regimes, we carried out our experiments with a research flume under controlled flow conditions.

\section{MATERIALS AND METHODS}

Posidonia oceanica shoots were collected from a meadow off Magalluf (Majorca, Spain) at $5 \mathrm{~m}$ depth and immediately transported in a refrigerated container to the flume facility located at the Netherlands Institute of Ecology (NIOO-KNAW), Yerseke, the Netherlands. Hydrodynamic properties and particletrapping rates of the canopy of $P$. oceanica were measured under controlled conditions in the racetrack flume, which is described in detail by Hendriks et al. (2006). Since $P$. oceanica leaves can grow to large size during the summer season, this experiment was conducted during the winter when the canopy height is minimal $(0.13 \pm 0.003 \mathrm{~m}$, mean leaf length $\pm \mathrm{SE}, \mathrm{n}=$ $214)$ in order to be able to use the flume $(0.40 \mathrm{~m}$ water depth). Plants bent at mean angles $( \pm \mathrm{SE})$ of $64.3^{\circ} \pm$ 3.58 and $58.7^{\circ} \pm 7.76$ to the flume bottom under flow velocities of 0.05 and $0.1 \mathrm{~m} \mathrm{~s}^{-1}$, respectively. Experiments were conducted from 14 February to 3 March 2005. Shoot and leaf densities in the test section (dimensions $2.1 \mathrm{~m}$ long $\times 0.6 \mathrm{~m}$ wide) were 118 to 120 and 761 to $785 \mathrm{~m}^{-2}$, respectively, in meadows constructed over 1.0 and $1.5 \mathrm{~m}$ length. Above ground biomass (leaves) was $119.5 \mathrm{~g} \mathrm{DW} \mathrm{m}^{-2}$. Water temperature was maintained at $14 \pm 0.2^{\circ} \mathrm{C}( \pm \mathrm{SE})$, comparable to that at the site of collection, while salinity was constant at 35\% (see Table 1 for experimental parameters). A seagrass canopy was planted in silica sand in the test-section, while a bare surface of silica sand alone was used as a control.

Water column leaf area index. Due to added biomass in this experiment, the frontal surface area of Posidonia oceanica leaves in the test section was $0.48 \mathrm{~m}^{2}$ for the $0.05 \mathrm{~m} \mathrm{~s}^{-1}$ treatment and $0.70 \mathrm{~m}^{2}$ for the $0.10 \mathrm{~m} \mathrm{~s}^{-1}$ treatment. Dividing this surface by the crosssectional area of the flume $(0.6 \times 0.4 \mathrm{~m})$ obtains an index similar to the Leaf Area Index (LAI), but for a specific vertical plane. This 'cross-sectional leaf area index', hereafter 'Leaf Filtration Index' (LFI), was 2.10 for the first velocity treatment and 3.05 for the higher velocity treatment (Table 1). 
Table 1. Experimental settings in the Netherlands Institute of Ecology (NIOO) flume: flow velocity in the water column $\left(U_{\infty}\right)$ for different treatments, Leaf Filtration Index (LFI, the ratio of leaf area divided by the cross-sectional area of the flume), density of leaves in the meadow constructed and initial particle load $\left(N_{0}\right)$ at the beginning of each experiment. Aboveground biomass was $120 \mathrm{~g} \mathrm{DW} \mathrm{m}^{-2}$

\begin{tabular}{|c|c|c|c|c|c|}
\hline $\begin{array}{l}\text { Date } \\
(\mathrm{d} / \mathrm{mo} / \mathrm{yr})\end{array}$ & $\begin{array}{l}\text { Experi- } \\
\text { ment }\end{array}$ & $\begin{array}{c}U_{\infty} \\
\left(\mathrm{m} \mathrm{s}^{-1}\right)\end{array}$ & LFI & \multicolumn{2}{|c|}{$\begin{array}{c}\text { Leaf density }\left(\mathrm{mg} \mathrm{l}^{-1}\right) \\
\left(\mathrm{m}^{-2}\right) \quad N_{0}\end{array}$} \\
\hline $18 / 02 / 05$ & Pos71 & 0.05 & 2.01 & 785 & 2575 \\
\hline 03/03/05 & Pos110 & 0.10 & 3.05 & 761 & 1576 \\
\hline $21 / 02 / 05$ & Silica sand & 0.05 & - & 0 & 1988 \\
\hline 01/03/05 & Silica sand & 0.10 & - & 0 & 1743 \\
\hline
\end{tabular}

Hydrodynamic properties of the canopy. Flow was measured with a Nortek Acoustic Doppler Velocimeter (ADV) (a field version of the Vector) mounted on a 3-dimensional positioning system where $x$ was defined as the main flow direction, $y$ across the flume channel and $z$ in the vertical direction. Two experimental free stream $\left(U_{\infty}\right)$ velocity treatments $(0.05$ and $0.10 \mathrm{~m} \mathrm{~s}^{-1}$ ) were applied. Time series of velocities were measured at a series of vertical positions ranging from close to the bed $(z=0.005 \mathrm{~m})$ to outside the boundary layer $(z=0.161 \mathrm{~m})$ when measuring over a sandy surface. Step size was $0.008 \mathrm{~m}$ for 0.005 to $0.101 \mathrm{~m}$, and $0.01 \mathrm{~m}$ for the last part of the profile $(0.101$ to $0.161 \mathrm{~m})$. For each position in the flow profile, 3-dimensional flow velocity measurements were sampled at a rate of $25 \mathrm{~Hz}$ over a period of $330 \mathrm{~s}$, resulting in ample resolution for turbulence calculations. Replicate velocity profiles were measured at 3 along-stream positions relative to the leading edge: $0.2 \mathrm{~m}$ in front of this edge, $0.2 \mathrm{~m}$ from the edge within the canopy and $0.2 \mathrm{~m}$ behind the last plants. From point measurements over time, the averages of individual velocity components $u, v$ and $W$ (corresponding to velocities in the $x, y$ and $z$ directions; $\mathrm{mm}$ $\mathrm{s}^{-1}$ ) were calculated; we also calculated turbulence kinetic energy (TKE, $0.5 \times\left(\overline{u^{\prime 2}}+\overline{v^{\prime 2}}+\overline{w^{\prime 2}}\right)$, in $\mathrm{mm}^{2} \mathrm{~s}^{-2}$ ) and the vertical flux of momentum, Reynolds stress $\rho\left(\overline{u^{\prime} w^{\prime}}\right)$ (in Pa or $\mathrm{N} \mathrm{m}^{-2}$ ), which may be considered as vertical transfer $\left(w^{\prime}\right)$ of longitudinal momentum fluctuations $\left(u^{\prime}\right)$ and an indicator of vertical mixing activity (Velasco et al. 2001). Negative Reynolds stresses indicate fluxes from the water column to the sediment which, according to the Reynolds' analogy for the equivalence of mass and momentum transfer in turbulent shear flow (Jobson \& Sayre 1970), can be also interpreted as transport of mass. Comparing profiles in control (sand) conditions and vegetated treatments gives an indication of increased transport of particles attributable to hydrodynamic changes caused by presence of the canopy.
Calculations of roughness height $\left(z_{0}, \mathrm{~mm}\right)$, and shear velocity $\left(u_{*}, \mathrm{~mm} \mathrm{~s}^{-1}\right)$ were made using the von Karman-Prandtl log-profile relationship:

$$
\bar{U}(z)=\frac{u_{*}}{\kappa} \ln \frac{z}{z_{0}}
$$

where $\bar{U}$ is the average flow speed at height $z\left(\mathrm{~mm} \mathrm{~s}^{-1}\right)$, and $\kappa$ is von Karman's constant $(\sim 0.41)$, by means of least squares regression of $\ln z$ on $\bar{u}$, as described by Gross \& Nowell (1983). Intuitively, $z_{0}$ is the height at which the mean velocity would drop to zero if the loglinear relation between $z$ and $U$ held so close to the bed. A plot of $\ln (z)$ against $u_{z}$ produces a straight line slope $\kappa / u$. for the near bed region under a steady, uniform boundary layer flow. The intercept of the graph was used to estimate the roughness height $\left(z_{0}\right)$. From flume measurements, 7 points from within the log layer were selected for each regression. These (flume) measurements were taken in the boundary layer at least $0.013 \mathrm{~m}$ away from the benthic surface to avoid boundary effects in measurements. Only 3 points were selected from above average canopy height measurements over the seagrass bed.

Particle retention in canopies. In addition to flow properties, particle retention was measured experimentally by measuring the particle load with 2 optical backscattering sensors (OBS) for all velocity treatments. For each experimental configuration, point measurements were obtained every $15 \mathrm{~min}$ from the OBS over 1440 consecutive minutes. No significant drift was observed in the output signal of the OBS between start and end points of the experiments. The OBS output was calibrated to obtain particle concentration profiles. Deep-sea sediment particles (size range ca. 1 to $3 \mu \mathrm{m}$, with negligible inherent vertical velocity $(w)$ calculated by Stoke's law as approximately $4 \times 10^{-6} \mathrm{~m} \mathrm{~s}^{-1}$ ) were seeded into the flume, and their concentration was measured in 15 min time intervals. Control measurements without plants were performed to obtain a background retention rate of the flume (i.e. loss of particles due to adhesion to the flume surface). Measurements were taken in the test-section both in front of and behind the canopy at $0.28 \mathrm{~m}$ above the sediment surface. The flume was mixed vigorously for 3 min before returning the settings to the treatment norm and taking measurements.

The loss rate of particles can be plotted as $N_{t}=a+$ $N_{0} \times \mathrm{e}^{-k t}$, where $N_{0}$ and $N_{t}$ are the particle loads at time 0 and time $t$, respectively, $a$ is the background concentration of the flume and $k$ is a first order rate constant. This equation should render a distinctive $k$ for a flume with and without plants if measurements are made on a sufficient time-scale. Measured constant $k$ when Posidonia oceanica is present is composed of an effective $k_{\mathrm{P}}$ attributable to the plants acting over the small 


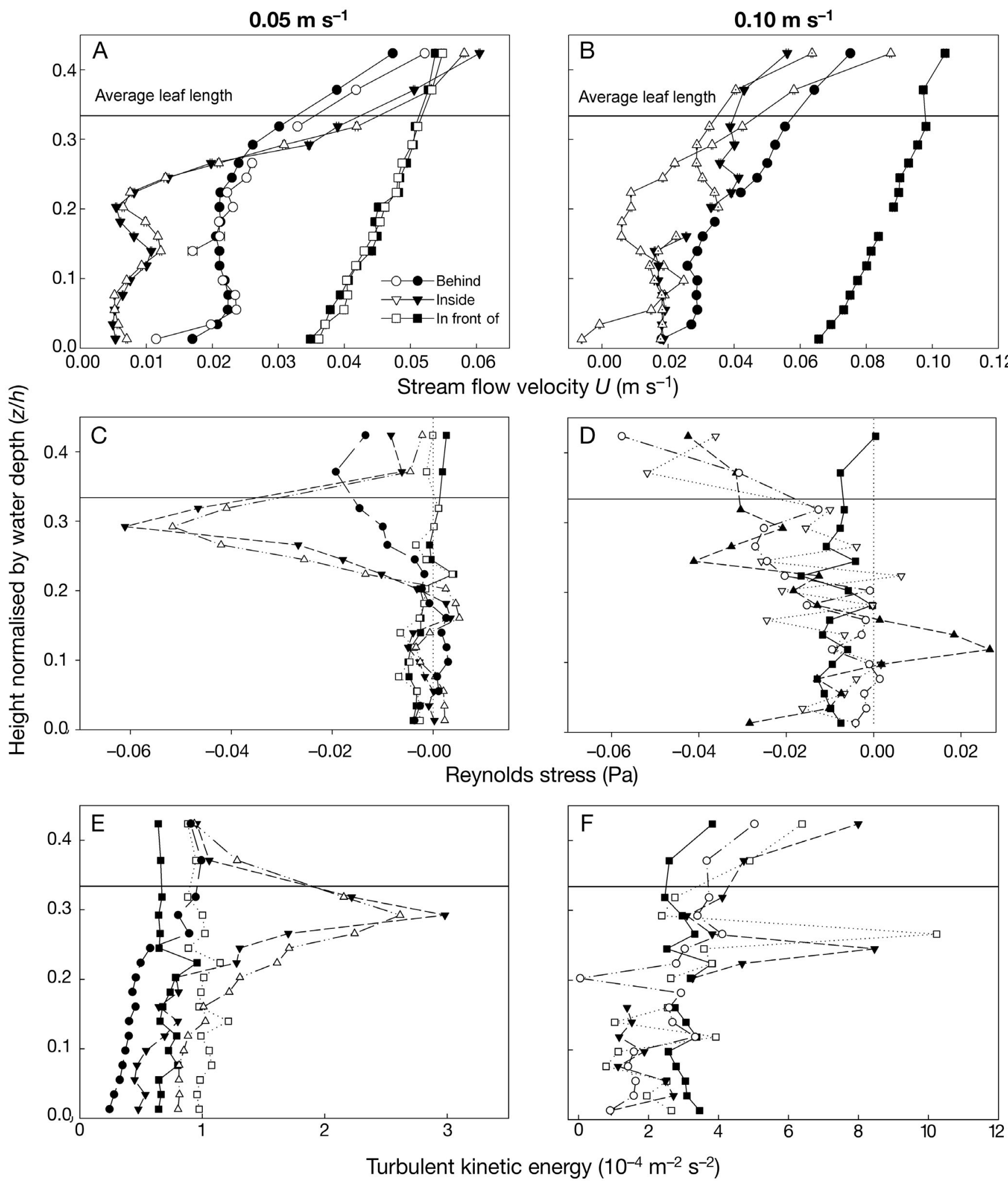

Fig. 1. Velocity profiles at free stream flow velocities $(U)$ of (A) 0.05 and (B) $0.10 \mathrm{~m} \mathrm{~s}^{-1}$ and Reynolds stress profiles under free stream flow velocities of (C) 0.05 and (D) $0.10 \mathrm{~m} \mathrm{~s}^{-1}$ with increased Reynolds stress (Pa) just below the average leaf length. Turbulent kinetic energy profiles under free stream flow velocities of (E) 0.05 and $(F) 0.10 \mathrm{~m} \mathrm{~s}^{-1}$ at measuring sites $0.2 \mathrm{~m}$ in front of the meadow leading edge, $0.2 \mathrm{~m}$ behind the leading edge and within the meadow, and $0.2 \mathrm{~m}$ behind the last plants in the seagrass canopy. On the $y$-axes, $z / h$ represents height $(z)$ normalised by overall water depth $(h)$ 
area where the meadow is present $(1.0$ to $1.5 \mathrm{~m})$ and the background loss rate for the remaining distance travelled in the flume measured for the empty flume ( $\left.k_{\mathrm{SAND}}\right)$. Since the flume has a length $L=41 \mathrm{~m}$, the time needed for the fluid to circulate once (one lap) at a given flow velocity $U_{\infty}\left(\mathrm{m} \mathrm{s}^{-1}\right)$ is $t_{1}=L / U_{\infty}$. The constant associated with the plants $k_{\mathrm{P}}\left(\mathrm{s}^{-1}\right)$ is therefore obtained by solving the equation:

$$
k_{\mathrm{SAND}} t_{\mathrm{s}}+k_{\mathrm{P}} t_{\mathrm{P}}=k t_{1}
$$

where $t_{\mathrm{P}}$ is the averaged time (s) the particle remains in the canopy. This time can be estimated as $t_{\mathrm{P}}=l_{0} / u_{\mathrm{P}}$ where $u_{\mathrm{P}}$ is the averaged velocity profile inside the canopy and $l_{0}$ is the length over which the meadow is constructed in the test-section $\left(1.0 \mathrm{~m}\right.$ for $U_{\infty} 0.05 \mathrm{~m} \mathrm{~s}^{-1}$ and $1.5 \mathrm{~m}$ for $U_{\infty}=0.1 \mathrm{~m} \mathrm{~s}^{-1}$, Fig. 1). With $k_{\mathrm{P}}$ we can now calculate the probability of particle retention upon hitting a leaf (taken as 2-sided) when a particle travels through the vegetated area according to:

$$
\frac{k_{\mathrm{P}} \cdot t_{\mathrm{P}}}{(2 \cdot \mathrm{LFI})}
$$

where LFI is a measure of the amount of leaves theoretically encountered by a particle when moving though this area.

\section{RESULTS}

\section{Hydrodynamic properties of the canopy}

Velocity profiles measured within the seagrass canopy clearly show the reducing effect of the shoots on flow velocity (Fig. 1A,B). Flow speeds within the canopy decreased 4 - to 13 -fold compared to normal flume conditions in front of the canopy, depending on the height of the measurement and velocity treatment. Calculation of fluxes for velocity profiles up to $0.16 \mathrm{~m}$ from the bottom as $\int_{z=0.16}^{z=0} \bar{U} \mathrm{~d} z$ (Gambi et al. 1990) indicated that volumetric flow through the canopy diminished to 30 and $40 \%$ of the control values for flow treatments at 0.05 and $0.10 \mathrm{~m} \mathrm{~s}^{-1}$, respectively.

Reynolds stress and turbulent kinetic energy (TKE) profiles peaked just below the average canopy height, confirming that this region is dynamically different from the lower canopy region (Fig. 1C-F). Vertical transport processes take place in this region specifically, which is consistent with other studies, e.g. Nepf (1999) and Ghisalberti \& Nepf (2002). When we integrated total Reynolds stresses generated in the water column (up to $0.16 \mathrm{~m}$ ), we observed ca. 2- to 6-fold increases in fluxes directed to the sediment when vegetation was present under 0.05 and $0.10 \mathrm{~m} \mathrm{~s}^{-1}$ velocity treatments (Fig. 1C,D). According to the Reynolds' analogy for equivalence of mass and momentum transfer in turbulent shear flow, we hypothesized a proportional increase in transport of mass (particles) as compared to fluxes to the sediment surface in the canopy treatment.

Shear velocity and roughness height were calculated (Table 2 ) according to the linear relation ( $\ln z$ versus $u$ ) resulting from Eq. (1). Values in front of the canopy were comparable to control conditions, indicating that all treatment effects were due to canopy presence only. Above the canopy (measurements within the canopy were not considered) high values for shear velocities were found. Since shear velocity relates in a quadratic manner to shear stress $(\tau)$ according to Formula 8.18 in Vogel (1994), $u_{*}=\sqrt{\tau / \rho}$, where $\rho$ is the density of the fluid), high shear stresses were present above the canopy. Behind the canopy, the log-relationship did not hold, and therefore shear velocity and roughness height could not be calculated reliably.

\section{Particle retention in canopies}

The exponential loss profiles showed particle retention in the flume to be an efficient process, even for an empty flume (Fig. 2), due to the large wall surface and the PVC tubes installed in the bends to smooth the flow (which further expanded the surface area). After 10 laps in the flume, there was no significant further decrease in particles and particle concentrations remained more or less stable. Posidonia oceanica canopies retained seeded particles more effectively than control conditions, as shown by calculated loss rate $k\left[\mathrm{~s}^{-1}\right]$ (Table 3 ) based on the exponential part of the graph. Interpreting and transforming this $k\left[\mathrm{~s}^{-1}\right]$ to a loss rate per circuit in the flume as $k\left[\operatorname{lap}^{-1}\right]$ showed

Table 2 . Average values of 2 profiles $(+\mathrm{SE})$ of shear velocity $\left(u_{*}\right)$ and roughness height $\left(z_{0}\right)$ along a gradient of positions $(0.2 \mathrm{~m}$ in front of meadow, $0.2 \mathrm{~m}$ from the leading edge within the meadow and $0.2 \mathrm{~m}$ behind the last seagrass plants) in the test-section at different free stream velocities $\left(U_{\infty}\right)$

\begin{tabular}{|llccccc|}
\hline \multirow{2}{*}{ Treatment } & \multirow{2}{*}{ Site } & $U_{\infty}\left(\mathrm{m} \mathrm{s}^{-1}\right)$ & \multicolumn{2}{c}{$u_{*}\left(\mathrm{~mm} \mathrm{~s}^{-1}\right)$} & \multicolumn{2}{c|}{$Z_{0}(\mathrm{~mm})$} \\
& & & Mean & SE & Mean & SE \\
\hline Posidonia & In front of & 0.05 & 2.15 & & 0.01 & \\
& & 0.10 & 3.74 & & 0.01 & \\
& Inside & 0.05 & 27.18 & 3.65 & 64.79 & 7.23 \\
& & 0.10 & 34.20 & 9.82 & 78.13 & 13.51 \\
& Behind & 0.05 & -0.21 & 0.06 & $\infty$ & \\
Sand & & 0.10 & 0.65 & & 0.00 & \\
& & 0.05 & 1.81 & 0.03 & 0.00 & 0.00 \\
& & 0.10 & 2.91 & & 0.00 & \\
\hline
\end{tabular}




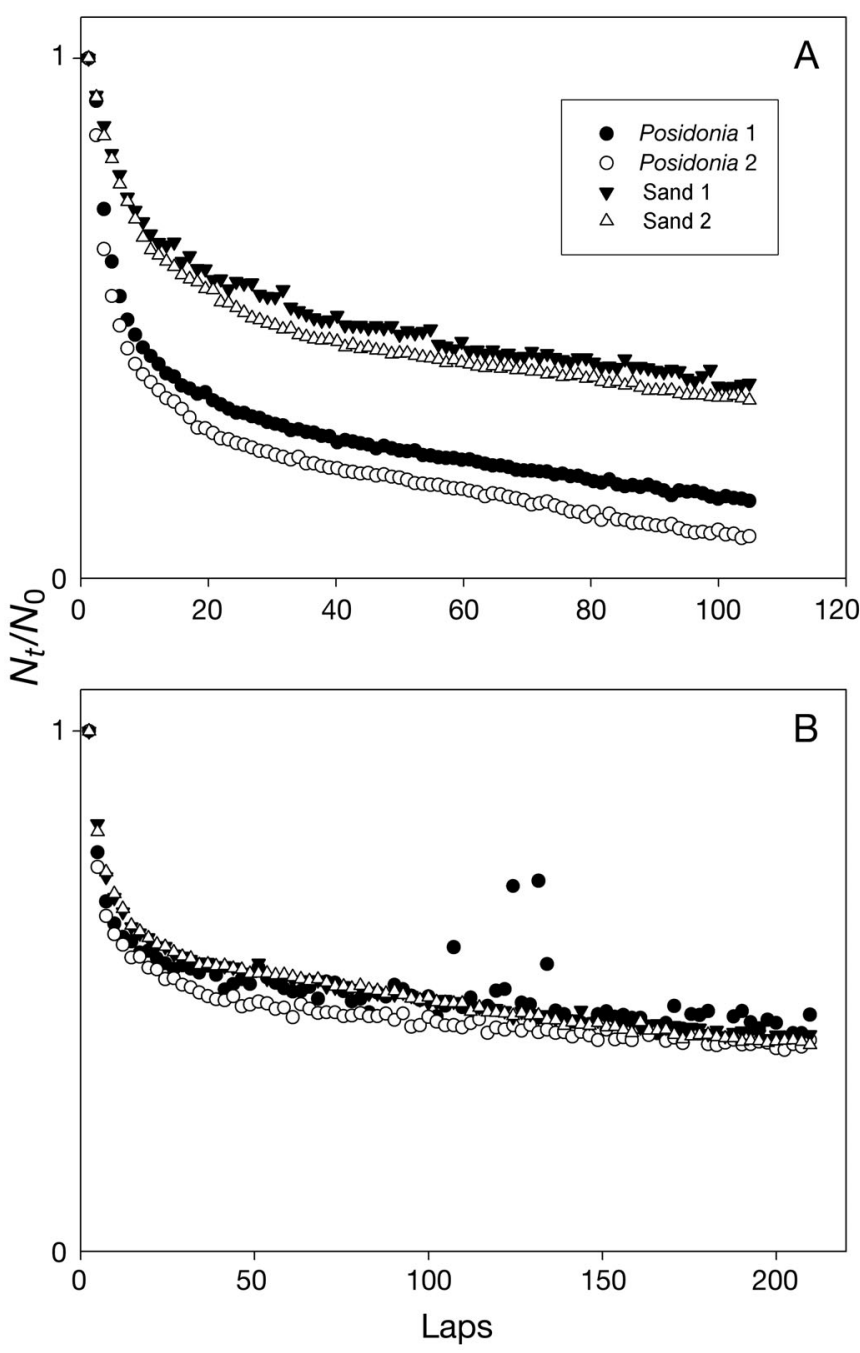

Fig. 2. Particle concentration (as $N_{t} / N_{0}$ ) in the flume under free stream flow velocities of (A) 0.05 and (B) $0.10 \mathrm{~m} \mathrm{~s}^{-1}$ at $0.10 \mathrm{~m}$ below the water surface for treatments with Posidonia oceanica and silica sand control along the test area. Laps are circuits around the circular flume that about $18 \%$ of the particles were lost per lap when a seagrass canopy was present compared to about $7 \%$ when the test-section was bare sand. Calculating the effective loss rate for the vegetation according to Eq. (2) resulted in loss rates an order of magnitude higher for the vegetated area $\left(2.57\right.$ to $2.59 \times 10^{-3}$ ) compared to sand $\left(1.02\right.$ to $\left.1.81 \times 10^{-4}\right)$ (Table 3$)$.

\section{Direct versus indirect particle trapping}

The particle loss rates obtained by separating whole flume retention from effective uptake by the vegetation resulted in disappearance rates an order of magnitude higher for the seagrass meadows (i.e. 14- to 25fold, Table 3). When we take our rough estimate from hydrodynamics only (by means of Reynolds stress), the presence of the Posidonia meadow should result in a 2 to 6-fold increase in particle uptake. We hypothesize that this discrepancy, which is roughly calculated and an approximation only, can be explained by the presence of leaves acting as physical obstacles. When we used calculated $k_{\mathrm{P}}$ to estimate the loss probability for a particle colliding with a leaf according to Eq. (3), which takes into account the times a particle would collide with a leaf when transiting the vegetated area in the flume, we found that individual particles have a 2 to $3 \%$ probability of being lost from the flow upon each collision with a seagrass leaf.

\section{Model formulation}

In order to explore and illustrate these direct processes leading to particle retention in the experimental seagrass canopy, we used a simple 2-dimensional numerical model. To enable us to highlight the mechanism of direct trapping via collisions of particles with

Table 3. (A) Estimates of fitted (best-fit exponential decay curves) particle disappearance rate ( $k$ in $\mathrm{s}^{-1} \pm \mathrm{SE}$ ) with $\mathrm{r}^{2}$ (for the exponential part of the graph) in duplicate $\left(k_{1}\right.$ and $\left.k_{2}\right)$, and calculated $k\left[\mathrm{lap}^{-1}\right]$ for one flume circuit. $P_{\text {diss }}$ hit ${ }^{-1}$ : estimated probability of disappearance following the collision of a particle with a leaf (in percent). (B) Estimates of the $k_{\mathrm{P}}$ value $\left(k_{\mathrm{P}}\left[\mathrm{s}^{-1}\right]\right)$ derived from Eq. (2) using the fitted particle disappearance rate during the experiment $\left(P_{\text {diss }}\right.$ hit $\left.^{-1}\right)$. $k_{\mathrm{SAND}}$ and $k_{\mathrm{POS}}$ are the average of the 2 measurements. The estimate velocity inside the canopy $u_{\mathrm{P}}$ is extracted from Fig. 1

\begin{tabular}{|c|c|c|c|c|c|c|c|c|}
\hline$U_{\infty}\left(\mathrm{m} \mathrm{s}^{-1}\right)$ & & & $r^{2}$ & & $\mathrm{~K}_{2} \pm \mathrm{SE}$ & $r^{2}$ & $k \operatorname{lap}^{-1}$ & $P_{\text {diss }}$ hit $^{-1}$ \\
\hline 0.05 POS & $2.46 \times 1$ & $.510 \times 10^{-5}$ & 0.93 & 2.7 & $-4 \pm 1.821 \times 10^{-5}$ & 0.92 & 0.19 & $3.12 \%$ \\
\hline 0.10 POS & $4.92 \times 1$ & $154 \times 10^{-5}$ & 0.71 & 4.1 & $\pm 3.561 \times 10^{-5}$ & 0.87 & 0.17 & $1.86 \%$ \\
\hline 0.05 SAND & $0.94 \times 1$ & $.502 \times 10^{-5}$ & 0.95 & & ${ }^{4} \pm 0.505 \times 10^{-5}$ & 0.96 & 0.07 & - \\
\hline 0.10 SAND & $2.02 \times 1$ & $880 \times 10^{-5}$ & 0.85 & 1.6 & $-4 \pm 1.580 \times 10^{-5}$ & 0.84 & 0.07 & - \\
\hline$u_{*}\left[\mathrm{~m} \mathrm{~s}^{-1}\right]$ & $t_{1}(\mathrm{~s})$ & $l_{0}(\mathrm{~m})$ & $u_{\mathrm{P}}\left(\mathrm{m} \mathrm{s}^{-1}\right)$ & $t_{\mathrm{P}}(\mathrm{s})$ & $k_{\mathrm{POS}}\left(\mathrm{s}^{-1}\right)$ & $k_{\mathrm{SAND}}\left(\mathrm{s}^{-1}\right)$ & \multicolumn{2}{|c|}{$k_{\mathrm{p}}\left(\mathrm{s}^{-1}\right)$} \\
\hline 0.05 & 820 & 1.0 & 0.020 & 50.00 & $2.59 \times 10^{-4}$ & $1.02 \times 10^{-4}$ & \multirow{2}{*}{\multicolumn{2}{|c|}{$\begin{array}{l}(2.57 \pm 0.38) \times 10^{-3} \\
(2.59 \pm 0.86) \times 10^{-3}\end{array}$}} \\
\hline 0.10 & 410 & 1.5 & 0.035 & 42.86 & $4.52 \times 10^{-4}$ & $1.81 \times 10^{-4}$ & & \\
\hline
\end{tabular}


leaves, we chose not to complicate the model by solving hydrodynamic equations and complex boundary conditions as present in the system and not to include diffusional deposition effects that usually take place in small-scale boundary layers. In other words, the model focuses only on sediment trapping by inertial impacts.

On a flat square surface of $1.0 \times 1.0 \mathrm{~m}$ representing a horizontal cut off of the canopy at height $z$, we initially placed a number of leaves at a density similar to the experimental leaf density (800 leaves $\mathrm{m}^{-2}$ ). The leaves were represented by $8 \mathrm{~mm}$ wide segments, equivalent to the mean leaf width, and were randomly oriented. A uniform laminar flow field was incorporated into the model system consistent with the averaged experimental flow velocities observed inside the canopy in the flume. For instance, for a free stream flow velocity of $u_{\mathrm{P}}=0.05 \mathrm{~m} \mathrm{~s}^{-1}$, an estimated velocity inside the canopy of $u_{\mathrm{P}}=0.02 \mathrm{~m} \mathrm{~s}^{-1}$ was considered. When a particle was released into the system, we assigned to this particle a unidirectional velocity $v=u_{\mathrm{P}}$ until it hit a leaf, upon which it was deflected. In addition to the initial change in the direction of the particle velocity due to reflection, inelastic collisions reduced the particle momentum due to friction in a fraction proportional to the particle incident velocity. The modulus of the new particle velocity was $\left|v_{\mathrm{NEW}}\right|=(1-\eta)\left|v_{\mathrm{OLD}}\right|$, with $\eta$ being

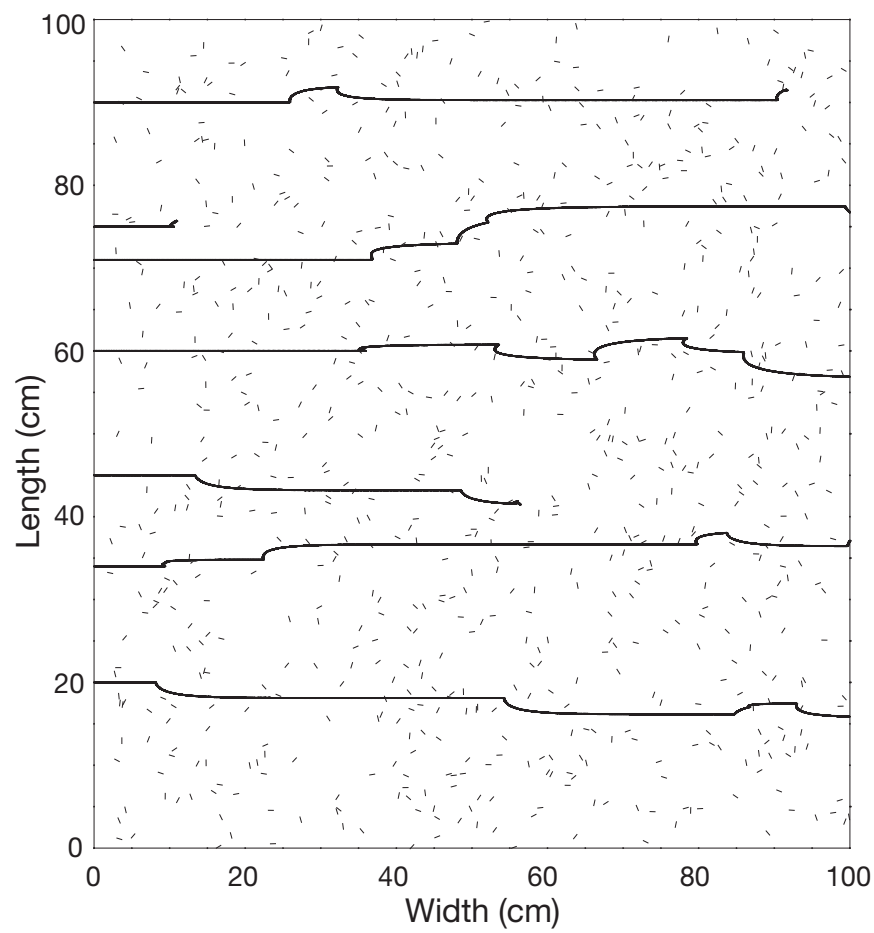

Fig. 3. Modeled particle trajectories (thick lines) through a Posidonia oceanica patch of $1 \times 1 \mathrm{~m}$ with randomly oriented leaves (short lines; density 800 leaves $\mathrm{m}^{-2}$ ). The model was run with an inside canopy velocity $\left(u_{\mathrm{P}}\right)$ of $0.02 \mathrm{~m} \mathrm{~s}^{-1}$ (corresponding to $U_{\infty}$ of $0.10 \mathrm{~m} \mathrm{~s}^{-1}$ ). Trajectories interrupted within the frame correspond to particles trapped within the canopies the fraction of momentum lost $(0<\eta<1)$. The value of $\eta$ was numerically estimated to the best fit with the experimental observations. In the time between 2 hits, the particle accommodated its velocity to the flow $u_{\mathrm{p}}$. The model followed the particle trajectory until the particle became trapped definitively or left the vegetation (particle trajectories visualized in Fig. 3). A particle became definitively trapped when sequential hits reduced its velocity below a given threshold value (i.e. $v<v_{\mathrm{TH}}$ ). In general it is very difficult to obtain experimental estimates of $v_{\mathrm{TH}}$ at which the particle (once in the viscous boundary layer) can be easily trapped by diffusion. We set a threshold velocity $v_{\mathrm{TH}}=0.0025 \mathrm{~m} \mathrm{~s}^{-1}$ and, because the threshold velocity value below which a particle was assumed to be captured can be seen as arbitrary, we tested model's sensitivity to the choice of this threshold. Changes in the number of particles for different threshold values were plotted (Fig. 4). Initially we started with $V_{\mathrm{TH}}=0.0025 \mathrm{~m} \mathrm{~s}^{-1}$, which is already about $1 / 10$ of the input flow velocity inside the canopy; $\eta$ was kept at 0.27 . For the rest of the threshold values, we have estimated the best fraction of momentum lost in order to get the best fit to the particle loss rate $k_{\mathrm{P}}$. We observed that reducing this threshold value by a factor of 2.5 or even 5.0 had very little effect on the fraction of momentum lost (Fig. 4), even though the lowest value of $v_{\mathrm{TH}}\left(0.0005 \mathrm{~m} \mathrm{~s}^{-1}\right)$ was so low that the particles were almost at rest. Higher values of $v_{\mathrm{TH}}$,

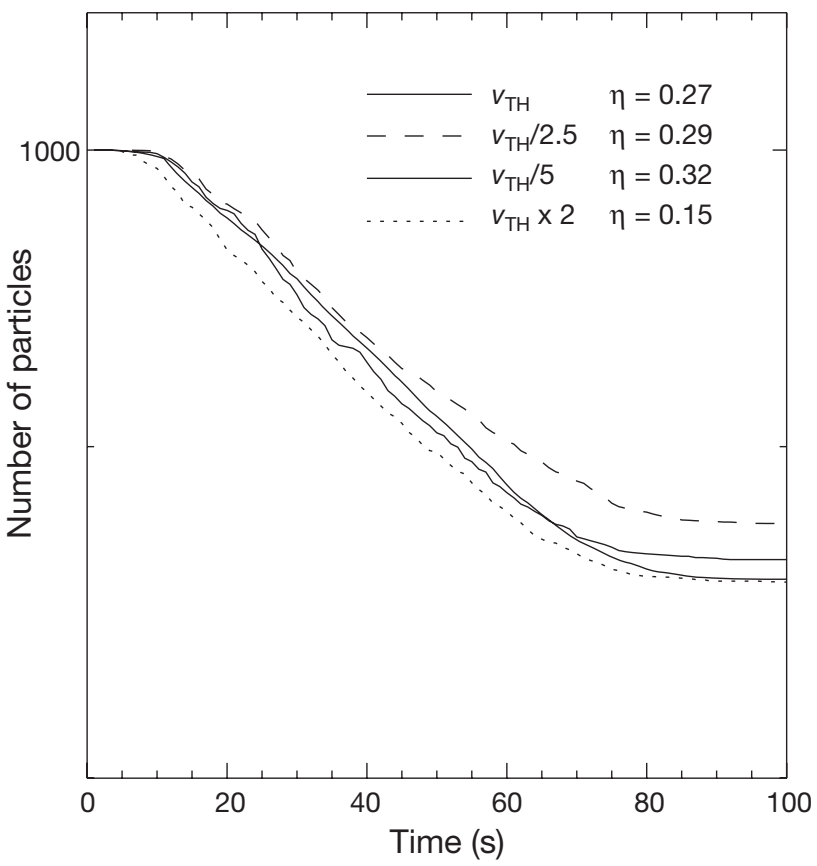

Fig. 4. Sensitivity analysis of threshold velocity $\mathrm{v}_{\mathrm{TH}}$ with leaf density 800 leaves $\mathrm{m}^{-2}$ and flow velocity $u_{\mathrm{P}}=0.02 \mathrm{~m} \mathrm{~s}^{-1} \cdot v_{\mathrm{TH}}$ was set at $0.0025 \mathrm{~ms}^{-1}$ and for each value, the best fraction of momentum loss $(\eta)$ was evaluated in order to obtain the best fit to the particle loss rate $k_{\mathrm{P}}$ 
such as a 2-fold increase, required a significant reduction of $\eta$. From this sensitivity analysis, we concluded that the threshold value of $v_{\mathrm{TH}}$ used in our simulations was well chosen, as it fell in the regime where no significant changes in the fraction of momentum lost were expected.

After releasing 1000 particles in the model, the number of remaining particles was recorded at regular time steps, allowing particle retention statistics comparable to those determined experimentally. The results of 100 model runs with different random canopy configurations were averaged. The model incorporated the most important experimental parameters, such as the leaf surface area (as LFI), leaf density, and the averaged observed flow velocity field inside the canopy. This allowed us to evaluate the required loss of particle momentum when a particle collided with a leaf in order to reproduce the experimentally observed loss rates.

\section{Model results}

Assuming that the loss of particles can be plotted as $N_{t}=N_{0} \times \mathrm{e}^{-k t}$, we estimated the fraction of particle momentum loss needed in order to reproduce the observed value of $k_{\mathrm{P}}=0.00257 \mathrm{~s}^{-1}$ (Table 3). Our best fit (Fig. 5A) gave us $\eta=0.27$ with a loss rate of $k_{\mathrm{P}}=$ $0.00235 \mathrm{~s}^{-1}$ (Table 4). For a fixed $\eta=0.27$, Table 4 summarizes the modeled $k_{\mathrm{P}}$ estimates at different flow velocities inside the canopy with different leaf densities. At moderate flow rates inside the canopy, the modeled $k_{\mathrm{P}}$ decreased with increasing flow, indicating that particles were lost more quickly under slower flow conditions (Fig. 5A). Simulation of the effects of varying leaf density on $k_{\mathrm{P}}$ at a given flow field (of $0.02 \mathrm{~m} \mathrm{~s}^{-1}$ inside the canopy) indicated that the rate of particle trapping increased with density of leaves (Fig. 5B), as expected. However, for faster flows $\left(>0.10 \mathrm{~m} \mathrm{~s}^{-1}\right)$ the model yielded unexpected results that do not conform to simple trends of particle trapping rates with increasing water velocity and leaf density. We observed that $k_{\mathrm{P}}$ increased at high flow velocities with moderate leaf densities. The reason is simple. If the flow field is strong enough, a particle colliding with a leaf is redirected towards the same leaf several times, increasing the probability of becoming trapped. We should emphasize that in order to obtain such high velocities inside a canopy, the external velocity applied has to be much higher than that experimentally investigated. Under such strong external forcing, seagrass leaves will bend, giving a completely different configuration that is not within the focus of current study.

We then set the numerical model to fit the loss of particle momentum for a particle hitting a leaf, to produce a particle loss rate similar to the experimentally obtained value of $k_{\mathrm{P}}$, which was the only fitted parameter in the model, all others being set by the experimental conditions. We predicted that when collisions accounted for particle loss only, approximately $27 \%$ of the particle momentum would be lost upon each collision with a leaf.

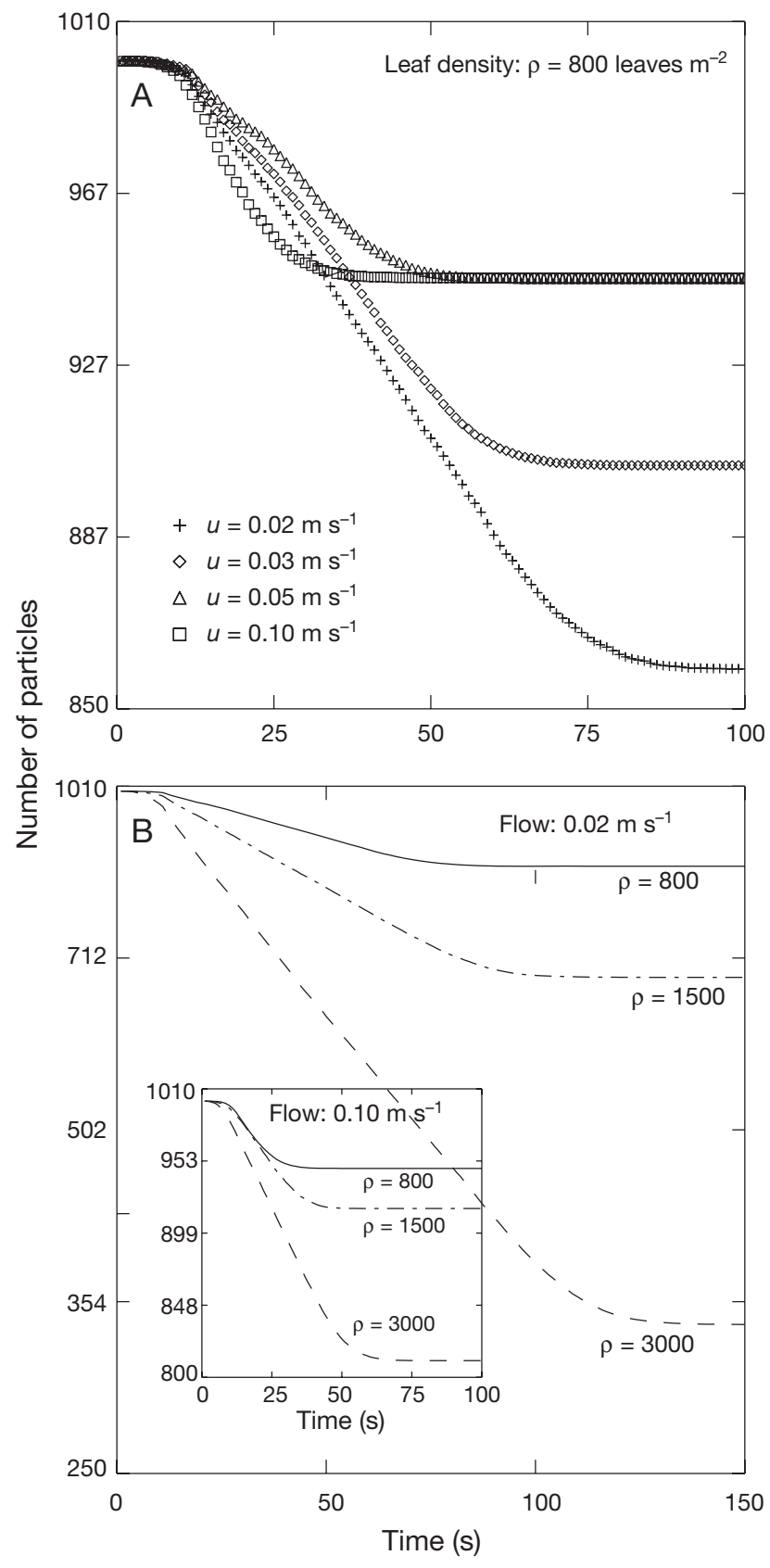

Fig. 5. Modeled particle concentrations over time for (A) a meadow with a density of 800 leaves $\mathrm{m}^{-2}$ at flow velocities of $0.02,0.03,0.05$ and $0.10 \mathrm{~m} \mathrm{~s}^{-1}$, and (B) a set flow velocity $\left(0.01 \mathrm{~m} \mathrm{~s}^{-2}\right)$ for meadows of densities 800, 1500 and 3000 leaves $\mathrm{m}^{-2}$ 
Table 4. Modeled particle loss rate $k\left(\mathrm{~s}^{-1}\right)\left(N=N_{0} \times \mathrm{e}^{-k t}\right)$ along the transit of particles over the canopy for different leaf densities and flow field velocities $\left(\mathrm{m} \mathrm{s}^{-1}\right)$ calculated for the vegetated area only. The last digits of the calculated particle loss rates (between parentheses) fall within the error estimates

\begin{tabular}{|lcccc|}
\hline \multirow{2}{*}{$\begin{array}{l}\text { Density } \\
\text { (leaves } \mathrm{m}^{-2} \text { ) }\end{array}$} & 0.02 & 0.03 & 0.05 & 0.10 \\
\hline 800 & $0.0023(5)$ & $0.0020(6)$ & $0.0015(4)$ & $0.0027(5)$ \\
1500 & $0.0047(6)$ & $0.0037(9)$ & $0.0028(2)$ & $0.0030(8)$ \\
3000 & $0.0105(5)$ & $0.0087(8)$ & $0.0064(7)$ & $0.0046(6)$ \\
\hline
\end{tabular}

\section{DISCUSSION}

We experimentally measured the effect of a seagrass canopy on flow dynamics and the role of the canopy in trapping suspended particles. Flow profiles within the canopy were measured relatively close to the leading edge $(0.2 \mathrm{~m})$, which may prevent full development of the hydrodynamic profiles. However, under slow velocity treatments such as those used here, we are confident that profiles obtained are representative for a seagrass meadow. Canopy effects on flow were qualitatively and quantitatively in agreement with literature reports (Ackerman 1983, 1986, Gambi et al. 1990, Gacia et al. 1999) and reviewed in Koch et al. (2006). Also, our results confirm the existence of 2 dynamically different environments: (1) the canopy-water interface region, characterized by high shear stress (shear velocity; Table 2) and turbulence intensity (Fig. 1E,F), and (2) the habitat within the canopy with low shear stress and reduced turbulence (Gambi et al. 1990, Nepf 1999, Ghisalberti \& Nepf 2002). In Region 1, turbulent vertical transport of momentum is enhanced (Ghisalberti \& Nepf 2002) due to augmented turbulent shear stresses (Velasco et al. 2001). Whereas these effects are adequately understood, the effects of canopies on particles have seldom been considered in flow dynamics studies and are largely derived from extrapolation of the effects of canopies on flow. This approach, though valuable, neglects the physical presence of the leaves themselves and their interaction with the suspended particles. Most particles transported within a seagrass canopy are likely to collide with the leaves (Ackerman 2002), which may lead to their capture, as demonstrated for salt-marsh vegetation consisting of Juncus roemerianus (Leonard et al. 1995) and Spartina alterniflora (Stumpf 1983), as well as for artificial structures mimicking plants (Hosokawa \& Horie 1992). Additional evidence of high particle trapping rates in seagrass meadows (Agawin \& Duarte 2002) suggests that physical filtration by plant structures plays a key role in particle removal in aquatic systems. However, the mechanisms responsible for particle trapping within seagrass meadows remain largely unclear.
The experiments described here provide strong indications that direct particle capture, a known phenomenon for terrestrial plants studied for air quality (Beckett et al. 1998), can also be an important mechanism for completely submerged vegetation like seagrass meadows. Our experimental results show a major loss of particles within the seagrass canopy compared with control conditions (bare sand), with the specific loss rates on transit through the vegetated area $\left(k_{\mathrm{P}}\right)$ strongly exceeding those over sand to a degree that cannot be explained by flow reduction alone. We propose that direct particle capture is an additional mechanism effectively trapping particles transported within reach of seagrass leaves as a result of canopy effects on overlying water movements. According to our model results (based upon loss through collisions), the transport of an individual particle across the experimental meadow involves the collision with, on average, 4 to 6 leaves, which leads to an estimated probability of particle loss from the flow upon a collision with a seagrass leaf of 2 to $3 \%$. These experimental results are, however, conservative relative to the results expected in the field, as the experimental leaf biomass (120 g DW $\mathrm{m}^{-2}$ ) was low compared to Posidonia oceanica meadows in the field (Duarte \& Chiscano 1999), which can extend over tens of kilometres. Furthermore, flow velocity will be severely reduced in denser canopies, so that the effect of increasing leaf density will even be greater with respect to their particle retaining properties.

Our results highlight the role of energy loss upon collisions between particles and seagrass leaves as a component additional to particle trapping caused by loss of momentum due to flow reduction. Water flow through the seagrass bed was 30 to $40 \%$ of control values, which is relatively high compared to literature values of around 10 to $30 \%$ for similar shoot densities (Gambi et al. 1990). When vegetation is present, vertical mixing activity increases fluxes directed to the sediment 2- to 6-fold. This flux takes into account only the hydrodynamic effects canopies have on flow, while trapping is caused by a combination of 2 separate processes: (1) the effects of the canopies on flows and (2) the effects derived from the collisions of particles with the leaves. When we separated only the effective retention of particles by the vegetation from whole flume effects, experimentally obtained particle-trapping rates were an order of magnitude higher. Even though these estimates are rough, they give sufficient cause to investigate another proposed mechanism for particle loss in canopies, which assumes particles lose energy and/or remain attached to leaves upon collision with the leaf surface. The model clearly does not represent reality since it models particle loss due to collision effects only, but this approach along with the 
commonly used explanation of particle retention by hydrodynamics alone gives us a valuable insight into alternative mechanisms.

Model analysis of the flume results indicated that, if the observed loss of particles in the flume were caused by collisions only, particles would lose about $27 \%$ of their energy upon a collision with a Posidonia oceanica leaf. This estimate is only theoretical, since the friction force that drags the particle depends on the viscosity of the fluid and on particle size and shape. As a consequence, the particle does not adapt instantaneously to the flow field after an inelastic collision with a leaf takes place (as assumed in our model). This makes the result difficult to translate to e.g. passive contaminants of the flow, as the geometry and size of the particles differed from that of molecules transported in the flow.

Key seagrass ecosystem functions include a role of meadows on sediment retention, protection of shoreline, shelter for a wide range of organisms (Heck et al. 2003), a role in maintenance of water quality (Hemminga \& Duarte 2000, Duarte 2002), and the role of seagrasses as major sites for carbon sequestration in the ocean (Gacia et al. 2002, Duarte et al. 2005). Seagrasses are known to enhance sedimentation and sediment retention, a process that has been linked to their effects on hydrodynamics (Terrados \& Duarte 2000, Gacia \& Duarte 2001, Marbà et al. 2006), but our results suggest enhancement through direct particle trapping by seagrass canopies. Effects of seagrass canopies on hydrodynamics are thought to facilitate larval retention in seagrass meadows (Koch et al. 2006). Our results suggest that direct retention of larvae through physical contact with seagrass leaves may also play a role. Seagrasses filter particles from the overlying water (Agawin \& Duarte 2002, Gacia et al. 2003, Marbà et al. 2006), maintaining water transparency and quality, thereby improving the light environment for seagrass growth. Our results suggest that direct particle trapping by the particle collisions with leaves contributes to this function. Seagrass meadows are a major site for carbon burial and sequestration in the biosphere (Duarte et al. 2005, Mateo et al. 2006), a function that may be largely dependent on particle trapping, as much of the organic carbon buried is derived from sestonic materials rather than seagrass carbon (Gacia et al. 2002, Kennedy et al. 2004, Papadimitriou et al. 2005).

In summary, the results presented here provide a mechanistic link between the known effects of seagrass on hydrodynamics (Koch et al. 2006) and additional particle filtering processes in the canopy, an important function of seagrass meadows in ecosystems. Water flow reduction by plants is not the only cause of particle sedimentation, and particle trapping by seagrass canopies is also induced by the physical collisions between the particles and the leaves, involving a probability that the particle will become attached to the leaf surface (Agawin \& Duarte 2002) or deposited in the meadow after major energy loss. Marine macrophytes present a diversity of canopy architectures, which may affect the efficiency of the particle trapping process demonstrated here for Posidonia oceanica as a model species. Investigation of variability among species may help in understanding the functions they perform in the ecosystem. The approach used here, combining flume experiments with modeling, may be successfully applied to other macrophyte species and even structure-building animals to provide a better understanding of the role of particle-object interactions in particle fluxes in coastal ecosystems.

Acknowledgements. This research was funded by a grant from the FBBVA and the European Network of Excellence MarBEF. We thank G. Tavecchia for help with analyses and J. van Soelen for preparing equipment and processing of samples. T.S. acknowledges project FIS2004-00953 from the Spanish government. C. Heip is gratefully acknowledged for permission to use the flume facilities at NIOO-KNAW, CEME.

\section{LITERATURE CITED}

Ackerman JD (1983) Current flow around Zostera marina plants and flowers: implications for submarine pollination. Biol Bull 165:504

Ackerman JD (1986) Mechanistic implications for pollination in the marine angiosperm Zostera marina. Aquat Bot 24:343-353

Ackerman JD (2002) Diffusivity in a marine macrophyte canopy: implications for submarine pollination and dispersal. Aquat Bot 89:1119-1127

Ackerman JD, Okubo A (1993) Reduced mixing in a marine macrophyte canopy. Funct Ecol 7:305-309

Agawin NSR, Duarte CM (2002) Evidence of direct particle trapping by a tropical seagrass meadow. Estuaries 25:1205-1209

Beckett KP, Freer-Smith PH, Taylor G (1998) Urban woodlands: their role in reducing the effects of particulate pollution. Environ Pollut 99:347-360

Bouma TJ, De Vries MB, Low E, Peralta G, Tanczos IC, van de Koppel J, Herman PMJ (2005) Trade-offs related to ecosystem engineering: a case study on stiffness of emerging macrophytes. Ecology 86:2187-2199

Duarte CM (2002) The future of seagrass meadows. Environ Conserv 29:192-206

Duarte CM, Chiscano CL (1999) Seagrass biomass and production: a reassessment. Aquat Bot 65:159-174

Duarte CM, Middelburg JJ, Caraco N (2005) Major role of marine vegetation on the oceanic carbon cycle. Biogeosciences $2: 1-8$

Fonseca MS, Cahalan JA (1992) Preliminary evaluation of wave attenuation by four species of seagrass. Estuar Coast Shelf Sci 35:565-576

Fonseca MS, Fisher JS, Ziemann JC, Thayer GW (1982) Influence of the seagrass, Zostera marina, L. on current flow. Estuar Coast Shelf Sci 15:367-380

Fonseca MS, Ziemann JC, Thayer GW, Fisher JS (1983) The 
role of current velocity in structuring eelgrass (Zostera marina L.) meadows. Estuar Coast Shelf Sci 17:367-380

Gacia E, Duarte CM (2001) Sediment retention by a Mediterranean Posidonia oceanica meadow: the balance between deposition and resuspension. Estuar Coast Shelf Sci 52:505-514

Gacia E, Granata TC, Duarte CM (1999) An approach to measurement of particle flux and sediment retention within seagrass (Posidonia oceanica) meadows. Aquat Bot 65:255-268

Gacia E, Duarte CM, Middelburg JJ (2002) Carbon and nutrient deposition in a Mediterranean seagrass (Posidonia oceanica) meadow. Limnol Oceanogr 47:23-32

Gacia E, Duarte CM, Marba N, Terrados J, Kennedy H, Fortes MD, Tri NH (2003) Sediment deposition and production in SE-Asia seagrass meadows. Estuar Coast Shelf Sci 56: 909-919

Gambi MC, Nowell ARM, Jumars PA (1990) Flume observations on flow dynamics in Zostera marina (Eelgrass) beds. Mar Ecol Prog Ser 61:159-169

Ghisalberti M, Nepf HM (2002) Mixing layers and coherent structures in vegetated aquatic flows. J Geophys Res 107(C2):1-11

Granata TC, Serra T, Colomer J, Casamitjana X, Duarte CM, Gacia E (2001) Flow and particle distributions in a nearshore seagrass meadow before and after a storm. Mar Ecol Prog Ser 218:95-106

Gross TF, Nowell ARM (1983) Mean flow and turbulence scaling in a tidal boundary layer. Cont Shelf Res 2:109-126

Heck KL Jr, Hays G, Orth RJ (2003) Critical evaluation of the nursery role hypothesis for seagrass meadows. Mar Ecol Prog Ser 253:123-136

Hemminga MA, Duarte CM (2000) Seagrass ecology. Cambridge University Press, Cambridge

Hendriks IE, van Duren LA, Herman PMJ (2006) Turbulence levels in a flume compared to the field: implications for larval settlement studies. J Sea Res 55:15-29

Hosokawa Y, Horie T (1992) Flow and particulate nutrient removal by wetland with emergent macrophyte. Sci Total Environ Suppl 1992:1271-1282

Jobson HE, Sayre WW (1970) Vertical transfer in open channel flow. J Hydraul Engin 96:703-724

Jumars PA, Eckman JE, Koch EW (2001) Macrosopic animals and plants in benthic flows. In: Boudreau BP, Jorgensen BB (eds) The benthic boundary layer: transport processes and biochemistry. Oxford University Press, Oxford, p 320-345

Kennedy H, Gacia E, Kennedy DP, Papadimitriou S, Duarte CM (2004) Organic carbon sources to SE Asian coastal sediments. Estuar Coast Shelf Sci 60:59-68

Koch EW (1996) Hydrodynamics of a shallow Thalassia testudinum bed in Florida, USA. In: Kuo J, Phillips RC, Walker DI, Kirkman H (eds) Seagrass biology. Proceed-

Editorial responsibility: Kenneth Heck,

Dauphin Island, Alabama, USA ings of an international symposium, Rottnest Island, Western Australia, p 105-110

Koch EW, Gust G (1999) Water flow in tide- and wave-dominated beds of the seagrass Thalassia testudinum. Mar Ecol Prog Ser 184:63-72

Koch EW, Ackerman JD, Verduin J, van Keulen M (2006) Fluid dynamics in seagrass ecology - from molecules to ecosystems. In: Larkum AWD, Orth RJ, Duarte CM (eds) Seagrasses: biology, ecology and conservation. Springer, Dordrecht, p 193-225

Leonard LA, Hine AC, Luther ME (1995) Surficial sediment transport and deposition processes in a Juncus roemerianus marsh, west-central Florida. J Coast Res 11:322-336

Lopez F, Garcia M (1998) Open-channel flow through simulated vegetation: suspended sediment transport modeling. Water Resour Res 34:2341-2352

Marbà N, Holmer M, Gacia E, Barrón C (2006) Seagrass beds and coastal biogeochemistry. In: Larkum AWD, Orth RJ, Duarte CM (eds) Seagrasses: biology, ecology and conservation. Springer, Dordrecht, p 135-157

Mateo MA, Cebrián J, Dunton K, Mutchler T (2006) Carbon flux in seagrass ecosystems. In: Larkum AWD, Orth RJ, Duarte CM (eds) Seagrasses: biology, ecology and conservation. Springer, Dordrecht, p 159-192

Nepf HM (1999) Drag, turbulence, and diffusion in flow through emergent vegetation. Water Resour Res 35: 479-489

Nepf HM, Vivoni ER (2000) Flow structure in depth-limited, vegetated flow. J Geophys Res 105:28547-28557

Palmer MR, Nepf HM, Pettersson TJR, Ackerman JD (2004) Observations of particle capture on a cylindrical collector: implications for particle accumulation and removal in aquatic systems. Limnol Oceanogr 49:76-85

Papadimitriou S, Kennedy H, Kennedy DP, Duarte CM, Marbà N (2005) Sources of organic matter in seagrass-colonized sediments: a stable isotope study of the silt and clay fraction from Posidonia oceanica meadows in the western Mediterranean. Org Geochem 36:949-961

Peterson CH, Luettich RA, Micheli F, Skilleter GA (2004) Attenuation of water flow inside seagrass canopies of differing structure. Mar Ecol Prog Ser 268:81-92

Stumpf RP (1983) The process of sedimentation on the surface of a salt marsh. Estuar Coast Shelf Sci 17:495-508

Terrados J, Duarte CM (2000) Experimental evidence of reduced particle resuspension within a seagrass (Posidonia oceanica L.) meadow. J Exp Mar Biol Ecol 243: 45-53

Velasco D, Bateman A, Redondo JM, DeMedina V (2003) An open channel flow experimental and theoretical study of resistance and turbulent characterization over flexible vegetated linings. Flow Turbul Combust 70:69-88

Vogel S (1994) Life in moving fluids, 2nd edn. Princeton University Press, Princeton, NJ

Submitted: October 6, 2006; Accepted: October 26, 2007

Proofs received from author(s): February 5, 2008 